\title{
All around biotechnology
}

\author{
A.N. Emery and A. Lyddiatt
}

Comprehensive Biotechnology: The Principles, Applications and Regulations of

Biotechnology in Industry, Agriculture and Medicine.

Editor-in-chief Murray Moo-Young.

Pergamon:1985. Four volumes, pp.3,764. £695, \$995.

BiotechNology feeds upon many disciplines, and is dependent upon the crossfertilization of ideas and information from a wide variety of sources. Ready access to the relevant literature is frequently inhibited by its style and format, and it is this drawback that is addressed by Comprehensive Biotechnology.

The work has been promoted as an integrated presentation of the basic principles, methods and applications of biotechnology. This is a formidable claim, and the fact that four volumes totalling over 3,500 pages were found to be necessary is a measure of the difficulty of the task that the editors set themselves. Moreover, the editorial board, under the direction of Murray Moo-Young, set out to assemble the work under several selfimposed constraints: they had to coordinate successfully an international team of 150 writers, combine intellectual appeal with comprehensive coverage and publish all four volumes at the same time. Such testing goals have been largely met in a work which lives up to its billing.

The four volumes are respectively entitled Scientific Fundamentals, Engineering Considerations, Current Commodity Products and Speciality Products and Service Activities, and each of them is in turn subdivided into either two or three sections. Volume 1 , Section 1 covers genetic and biological fundamentals (including isolation methods, nutrition, growth and death of microorganisms as well as their genetic manipulation), while the regulation of cellular metabolism and enzyme evolution, mechanisms and kinetics are dealt with in Section 2. The introduction rightly describes this as a "pedagogic academic coverage" of the scientific disciplines underpinning the field as a whole, but the absence of stuffiness in the prose or inhibitory jargon is a strong incentive for the reader to explore the text rather than merely use it for reference. The relatively low-key coverage of animal and plant cell culture (combined in one lone chapter), however, reflects an emphasis out of keeping with the rapid increase of activity in these areas.

Volume 2 contains sections on bioreactor design, operation and control, and on upstream and downstream processing, written by a varied group of academic and industrial authors. This mix is not wholly successful, because some of the contri- butors have been allowed to reflect rather too strongly their commercial affiliations. Also, a stricter editorial hand would have avoided the repetition found, for example, in all four chapters on instrumentation, data handling and control, as well as in four chapters on aspects of membrane-based processes. Crossreferencing both between operations described within Vol. 2, and with applications in Vol. 3, would have greatly added to the value of these two components of the work.

Volumes 3 and 4 are described in their introductions as "utilitarian practical account[s] of commercial processes and products". The authorship is truly international (except for Soviet and Eastern European representation), and is largely drawn from industry. Volume 3 gives good accounts of present practices in the development and manufacture of healthcare products, food and beverage products, and industrial chemicals, biochemicals and fuels. Volume 4 is much more illassorted: the first section, in particular, while aiming to introduce potential applications in biomedicine and chemotherapy, agriculture and other areas, is also left to pick up pieces of instrumentation, detection and containment of biohazards, and even surface thermodynamics. The remaining two sections give, first, an interesting and helpful international comparison of governmental approaches to both support and regulation of biotechnology, and lastly a useful blend of the theory and practice of waste management and pollution control.

It would need a football team of specialists to provide a detailed evaluation of the diverse contents of these four volumes. Instead, we sought to assess Comprehensive Biotechnology by making it available in our laboratories for anyone who cared to consult it - academic and research staff, students and industrial collaborators with interests across a wide range of subjects. By and large, their response has been enthusiastic. Specialists have generally judged the treatments of their own areas to be thorough, well illustrated, topical and generously referenced (up to about mid-1983). Venturing into lessfamiliar areas, we and our colleagues have found ourselves neither patronized by too shallow a text nor left floundering, bereft of explanation or definition. Each volume includes a glossary of terms and is individually indexed, though only Vol. 4 contains a cumulative index to the work as a whole - indeed, a general lack of intervolume cross-referencing is a weakness. There is surely a strong case for producing a separate cumulative index.

Our personal expertise is in biochemical engineering, so it is inevitable that our more detailed criticisms arise with Vol. 2, and particularly the section on upstream and downstream processing. Here there are some surprising omissions, for example protein precipitation, non-specific adsorption, evaporation and drying. Such operations are now widely used in biochemical recovery, and absence of discussion of them is puzzling. This, however, could well be rectified in the subsequent, "update" volumes which the editors promise will appear at intervals to chronicle the scientific and technical developments of the future. Inclusion of an overview of the integration of unit processes in production and recovery operations would be beneficial, as would coverage of topics such as multiphase mixing,

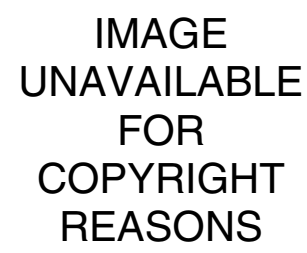

Bacterial change - a phase-contrast photomicrograph of spores and vegetative cells of Bacillus fastidiosus. The picture is reproduced from Developmental Biology of the Bacteria, by Martin Dworkin, published by Benjamin/Cummings. Price is \$31.95, £24.95. 